\title{
Omniphobic Membrane for Robust Membrane Distillation
}

\author{
Shihong Lin, ${ }^{\dagger}$ Siamak Nejati, ${ }^{\dagger}$ Chanhee Boo, ${ }^{\dagger}$ Yunxia Hu,${ }^{\dagger}$ Chinedum O. Osuji, ${ }^{\dagger}$ \\ and Menachem Elimelech ${ }^{* \dagger}$ \\ ${ }^{\dagger}$ Department of Chemical and Environmental Engineering, Yale University, New Haven, Connecticut 06520-8286, United States \\ \#Yantai Institute of Coastal Zone Research, Chinese Academy of Sciences, Yantai, Shandong 264003, China
}

\author{
Supporting Information
}

\begin{abstract}
In this work, we fabricate an omniphobic microporous membrane for membrane distillation (MD) by modifying a hydrophilic glass fiber membrane with silica nanoparticles followed by surface fluorination and polymer coating. The modified glass fiber membrane exhibits an antiwetting property not only against water but also against low surface tension organic solvents that easily wet a hydrophobic polytetrafluoroethylene (PTFE) membrane that is commonly used in $\mathrm{MD}$ applications. By comparing the performance of the PTFE and omniphobic membranes in direct contact MD experiments in the presence of a surfactant (sodium dodecyl sulfate, SDS), we show that SDS wets the hydrophobic PTFE membrane but not the omniphobic membrane. Our results suggest that omniphobic membranes are critical for MD applications with feed waters containing surface active species, such as oil and gas produced water, to prevent membrane pore wetting.

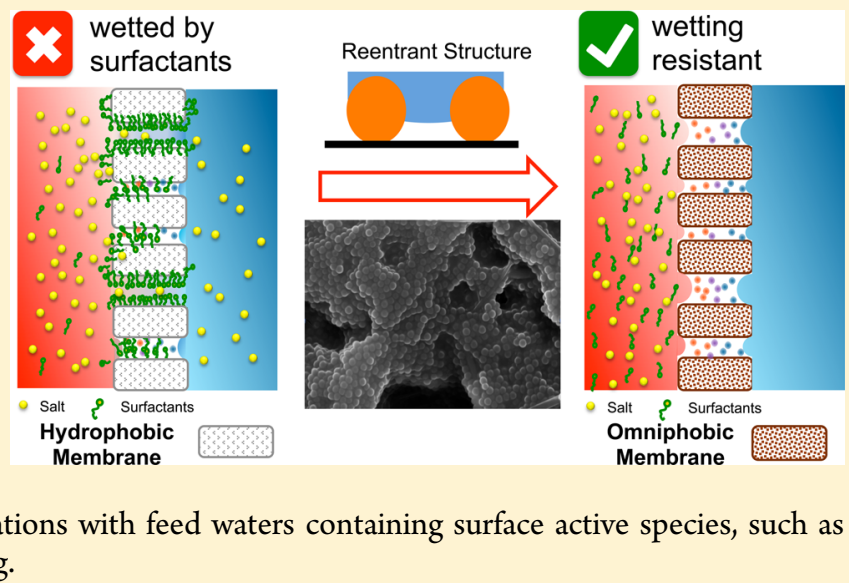

\section{INTRODUCTION}

Membrane distillation (MD) is a thermal separation process using a microporous hydrophobic membrane. ${ }^{1-3} \mathrm{MD}$ can operate at relatively low temperatures and is thus able to tap into the vast amount of low-grade waste heat. ${ }^{4-6} \mathrm{MD}$ is also advantageous over pressure-driven membrane processes, such as reverse osmosis ( $\mathrm{RO}$ ) or nanofiltration, as its low operating pressure reduces the capital cost due to the absence of expensive components, such as high pressure pumps and vessels, as well as pressure exchangers. Recently, MD has been proposed as a low-temperature thermal separation component for hybrid membrane processes coupled with forward osmosis for simultaneous wastewater reuse and mineral recovery ${ }^{7,8}$ and with pressure retarded osmosis for harvesting low-grade waste heat. $^{\text {? }}$

Although $\mathrm{MD}$, as any thermal separation process, is inherently less energy efficient than $\mathrm{RO}^{10,11}$ there exist scenarios in which MD may be preferred. For example, if an abundant amount of waste heat or solar thermal energy is readily available, $\mathrm{MD}$ can be employed to utilize such low-grade heat to considerably reduce the energy cost and carbon footprint for desalination compared to $\mathrm{RO}$ powered by conventional energy sources. ${ }^{12-14} \mathrm{MD}$ can also be used to desalinate high salinity brines, such as shale gas wastewater, as the osmotic pressure of such brines is far beyond the allowable pressure in RO operations. ${ }^{15}$ In addition, MD can be employed for small-scale desalination in remote regions for which $\mathrm{RO}$ is not an option due to its dependence on grid power and costly high-pressure components that are not readily adaptable for small-scale systems.

In $\mathrm{MD}$ desalination, a hydrophobic membrane is employed to create a vapor gap that separates a salty feed solution and the desalted permeate solution. ${ }^{16}$ It is critically important that the membrane pores are not wetted by the feed solution as liquid flooding of the pores destroys the vapor gap and undermines the function of the membrane as a selective barrier for salt passage. ${ }^{1,17,18}$ Preventing pore wetting is particularly challenging in desalinating shale gas wastewater or other feed waters with high levels of surfactants or low surface tension contaminants, ${ }^{19,20}$ which may significantly reduce the pore liquid entry pressure. To overcome this problem, it is imperative to develop a novel MD membrane that resists wetting by not only water but also other low surface tension substances. Toward this goal, novel MD membranes such as composite hydrophilic-hydrophobic membranes ${ }^{21}$ and superhydrophobic membranes ${ }^{22}$ have been developed to mitigate wetting.

Recent advances in understanding natural surfaces with special wettability have driven the development of artificial surfaces with similar wetting properties using biomimetic approaches. ${ }^{23-28}$ A representative example is an omniphobic surface that repels both water (i.e., hydrophobic) and low

Received: August 28, 2014

Revised: September 28, 2014

Accepted: September 30, 2014

Published: September 30, 2014 
surface tension liquids such as oil (i.e., oleophobic). ${ }^{29-32}$ The omniphobicity is realized by creating surfaces with low surface tension and microscopic reentrant structures that together facilitate the existence of the metastable Cassie-Baxter state for the liquid-solid-vapor interfaces. ${ }^{29,33,34}$ A variety of methods have been employed to create or modify surfaces of numerous substrate materials to impart surface omniphobicity. ${ }^{30-32,35-38}$ We propose that an omniphobic microporous membrane can serve as an MD membrane with excellent wetting resistance. However, to date, no omniphobic microporous membrane has been developed for $\mathrm{MD}$ applications.

In this study, we fabricate an omniphobic membrane for $\mathrm{MD}$ by coating a hydrophilic glass fiber membrane with silica nanoparticles, followed by subsequent surface fluorination and polymer coating. The fabricated omniphobic membrane is then compared to a hydrophobic commercial PTFE membrane for their anti-wetting properties against liquids of a wide range of surface tensions. Direct contact membrane distillation (DCMD) experiments are also conducted using both the omniphobic and PTFE membranes to compare their antiwetting performances in the presence of a commonly used surfactant, sodium dodecyl sulfate (SDS).

\section{MATERIALS AND METHODS}

Modification of Glass Fiber Membrane. The membrane substrate is a microporous glass fiber (GF) membrane with a nominal pore size of $0.7 \mu \mathrm{m}$ and an average thickness of 420 $\mu \mathrm{m}$ (GF/F, GE Healthcare, NJ). The GF membrane is highly hydrophilic and can be easily wetted by water. We have selected the GF membrane as the substrate as it allows surface modifications using well-established silane chemistry.

A five-step method was used to modify the hydrophilic GF membrane to become omniphobic (Figure S1, Supporting Information). First, the negatively charged borosilicate GF was treated with 3-aminopropyl-triethoxysilane (APTES) in toluene. The APTES covalently binds to the GF via hydrolysis to render the fibers positively charged at near neutral $\mathrm{pH}^{39}$ The APTES-coated GF membrane is then immersed in an aqueous suspension of silica nanoparticles (SiNPs) prepared using the Stöber method (details in Supporting Information). ${ }^{40}$ The negatively charged SiNPs adsorb onto the positively charged APTES-coated GF membrane via electrostatic interaction. To strengthen the binding between the SiNPs and glass fibers, the SiNP-coated GF membrane was briefly treated with a toluene solution of silicon tetrachloride $\left(\mathrm{SiCl}_{4}\right)$. The $\mathrm{SiCl}_{4}$ hydrolyzes even in the presence of a trace amount of water, fusing the contact regions between the SiNPs and GF and between the SiNPs themselves. ${ }^{39}$

After attaching the SiNPs to the glass fibers, the modified GF membrane was treated by fluorinated alkyl silane (FAS) dissolved in hexane. ${ }^{36}$ The FAS reacts with the silica surface via a hydrolysis reaction, resulting in a fluorinated GF membrane of significantly reduced surface tension compared to that of a GF membrane before fluorination. The fluorinated GF membrane was then briefly immersed in a solution of poly(vinylidene fluoride-co-hexafluoropropylene) and FAS dissolved in dimethylformamide (DMF). ${ }^{38}$ Finally, the modified membrane was subjected to heat treatment at $130{ }^{\circ} \mathrm{C}$ for $1 \mathrm{~h}$. More details on the surface modification procedure can be found in the Supporting Information.

Membrane Characterization. We compared the wetting properties of our fabricated omniphobic membrane and a commercial PTFE membrane. The PTFE membrane, with a nonwoven polyester support layer, has a nominal pore size of $0.45 \mu \mathrm{m}$ and an average thickness between 198 and $269 \mu \mathrm{m}$ (PTF045-LHOP, Pall Corporation, NY). We measured the contact angles for these membranes with pure liquids with a wide range of surface tensions, including water $(\gamma=72.8 \mathrm{mN} /$ $\mathrm{m})$, mineral oil $(\gamma \approx 30 \mathrm{mN} / \mathrm{m})$, decane $(\gamma=23.8 \mathrm{mN} / \mathrm{m})$, and ethanol $(\gamma=22.1 \mathrm{mN} / \mathrm{m})$. Due to the dynamic behavior of the sessile drops for certain tested liquids, the initial contact angles as well as the time for the contact angles to become less than $10^{\circ}$ were recorded.

Membrane Performance Testing. We conducted comparative DCMD experiments for the commercial PTFE membrane and the fabricated omniphobic membrane. The DCMD experiments were performed on a small membrane coupon $(6 \mathrm{~cm} \times 2 \mathrm{~cm})$ in a cross-flow lab-scale test unit (details in Supporting Information). We have used 1.0 M NaCl as the feed solution and deionized water as the permeate (or distillate) solution with temperatures of 60 and $20{ }^{\circ} \mathrm{C}$, respectively. During the course of the $9 \mathrm{~h}$ long DCMD experiments, sodium dodecyl sulfate (SDS) was added to the feed solution to progressively reduce the surface tension of the feed solution. The SDS concentrations of the feed solution after sequential additions were $0.1,0.2,0.3$, and $0.4 \mathrm{mM}$. The increase in the weight of the permeate solution was monitored to calculate the water (vapor) flux, $J_{\mathrm{W}}$, across the membrane. The electrical conductivity of the permeate solution was measured to assess the $\mathrm{NaCl}$ concentration in the permeate solution from which the salt flux, $J_{\mathrm{S}}$, and salt rejection, $R$, were calculated.

To facilitate the detection of membrane pore wetting, we applied a higher cross-flow rate in the feed solution $(0.4 \mathrm{~L} / \mathrm{min}$, or a crossflow velocity of $8.5 \mathrm{~cm} / \mathrm{s}$ ) than in the permeate solution $(0.2 \mathrm{~L} / \mathrm{min}$, or a crossflow velocity of $4.3 \mathrm{~cm} / \mathrm{s})$ to generate a higher hydraulic pressure for the feed. ${ }^{22}$ The pressure difference across the membrane was confirmed by visual observation of the membrane being pressed against the permeate spacer in a transparent test cell. With such an experimental setup, if some membrane pores are wetted, the transmembrane pressure difference would drive the feed solution through the wetted portions of the membrane, as in microfiltration, leading to significantly increased water flux and reduced salt rejection.

\section{RESULTS AND DISCUSSION}

Morphology and Wetting Properties of the Omniphobic Membrane. The omniphobic membrane has a radically different surface morphology compared to the pristine GF membrane due to presence of the SiNPs (Figure 1). It is evident from the SEM image that SiNPs not only coat the surface of the glass fibers but also form aggregates that cover some of the membrane pores. These SiNPs aggregates create a multi-scale reentrant structure that sustains a metastable Cassie-Baxter thermodynamic state, in which the liquid is supported by a composite interface consisting of both the solid surface and the vapor/air entrapped between the solid structures. $^{39}$ Because air itself is strongly omniphobic, the composite surface exhibits a significantly improved anti-wetting property as illustrated by the comparison of the contact angles between the fabricated omniphobic membrane and the hydrophobic PTFE membrane.

The omniphobic and PTFE membranes have similar high sessile drop contact angles with water. However, whereas mineral oil, ethanol, and decane all wetted the PTFE 


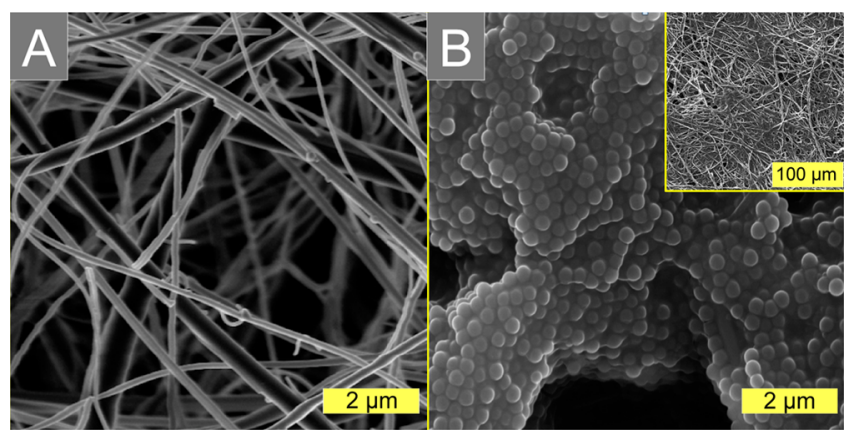

Figure 1. SEM images featuring the local morphology of (A) a GF membrane and (B) an omniphobic membrane after the five-step modification procedure. The inset image in $\mathrm{B}$ shows the morphology of a large piece of the omniphobic membrane.

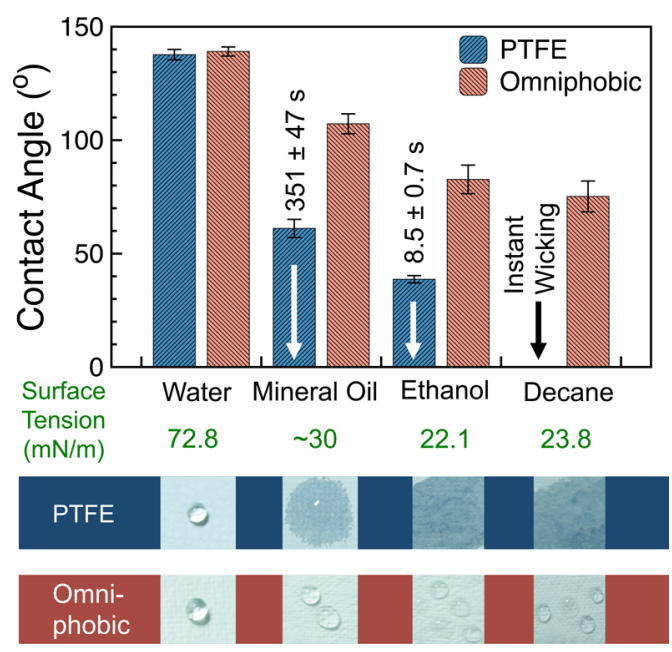

Figure 2. Comparison of contact angles between the omniphobic membrane and the hydrophobic PTFE membrane with liquids of different surface tensions (indicated in green below the liquids). Photographs of the wetting behavior for both membranes are also given underneath the bar chart. The darker area on the PTFE membrane represents portions of the membrane that are wicked. No stable contact angle was measurable for the PTFE membrane with mineral oil, ethanol, and decane, as the liquids wick the PTFE membrane either instantly or in a relatively short time (time scale is given in the bar chart). The contact angles for the omniphobic membrane with ethanol and decane also decrease slowly with time due to fast liquid evaporation and contact angle hysteresis. No wicking was observed for the omniphobic membrane with any tested liquid. The error bars represent standard deviations of 12 contact angles from 6 measurements (each measurement includes both left and right contact angles).

membrane, they did not wet the omniphobic membrane (Figure 2). The wetting of the PTFE membrane with mineral oil and ethanol is dynamic; the liquids initially beaded up upon contact with the membrane as drops with measurable contact angles but then penetrated into the porous membrane and propagated along the membrane surface with observable wetting fronts as shown in the photographs at the bottom of Figure 2. With decane, on the other hand, instant complete wicking of the PTFE membrane was observed with no measurable positive contact angle.

In contrast, the omniphobic membrane was not wetted by any of the tested liquids. Although the initial contact angles for the omniphobic membrane with ethanol and decane were below $90^{\circ}$ and decreased with time due to fast evaporation, no wicking was observed. The liquid-air-solid triple-phase boundary remained unaltered, and the opposite side of the membrane remained dry, indicating that the fabricated omniphobic membrane is anti-wetting, even against low surface tension liquids (i.e., oleophobic).

Membrane Performance in DCMD. The fabricated omniphobic membrane and hydrophobic PTFE membrane were tested in DCMD experiments in which SDS was introduced into the feed solution with progressively increasing concentrations. With the hydrophobic PTFE membrane, the wetting phenomenon was obvious as indicated by the drastically increased water flux and reduced salt rejection (open blue and red circles, respectively, in Figure 3). Even at

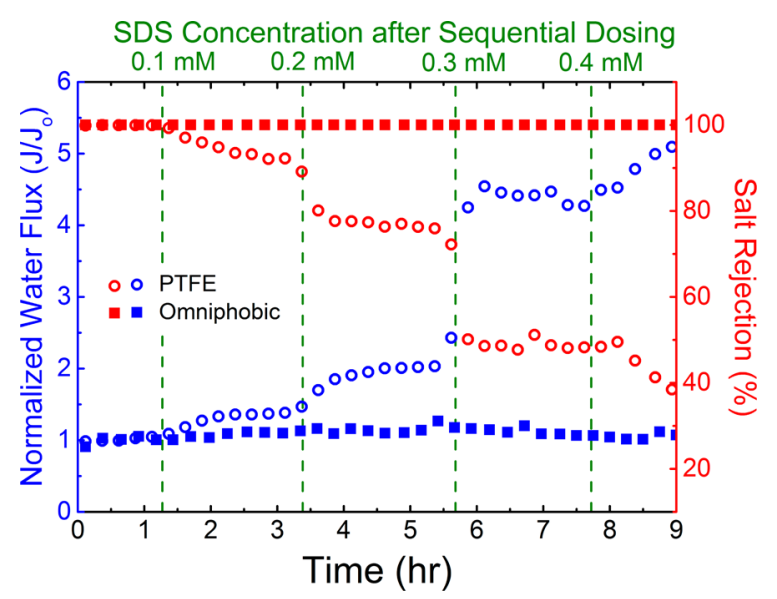

Figure 3. Water flux and salt rejection for our fabricated omniphobic membrane and commercial PTFE membrane at different SDS concentrations as observed in the DCMD runs. The water fluxes are normalized by the initial vapor fluxes. The green dashed lines represent the addition of SDS with the SDS concentrations in the feed solution after the each addition indicated at the top. The crossflow velocities in the DCMD test cell channel were 8.5 and $4.3 \mathrm{~cm} / \mathrm{s}$ in the feed (hot) and permeate (cold) stream channels, respectively. Temperatures of the feed and permeate streams were 60 and $20^{\circ} \mathrm{C}$, respectively. The initial water vapor fluxes $\left(J_{0}\right)$ for the PTFE membrane and omniphobic membrane were $32.6 \pm 1.5$ and $15.8 \pm$ $2.7 \mathrm{Lm}^{2-} \mathrm{h}^{-1}$, respectively. The difference arises primarily because the omniphobic membrane is almost twice as thick as the PTFE membrane.

the lowest SDS concentration tested $(0.1 \mathrm{mM})$, the water flux of the PTFE membrane has already started to increase due to pore wetting. Wetting became progressively more severe as the SDS concentration of the feed solution increased, with water flux increasing more than five folds and salt rejection dropping to $40 \%$ at $0.4 \mathrm{mM}$ SDS.

If the PTFE membrane were fully wetted, the PTFE membrane would have behaved as a microfiltration membrane with no salt rejection. The partial wetting phenomenon can be explained by the distribution of liquid entry pressures due to heterogeneous pore size distributions. ${ }^{17}$ As the surface tension was reduced due to increasing SDS concentration, some larger pores became flooded by the SDS solution because their liquid entry pressures were reduced to levels lower than the hydraulic pressure in the feed channel. We note that our experimental observation is only qualitatively meaningful, as wetting of the PTFE membrane in real-world applications should depend not 
only on the SDS concentration but also the hydraulic pressure in the feed channel.

In comparison, the performance of the omniphobic membrane in DCMD was very robust, even in the presence of surfactants. The addition of SDS had no observable effect on the water vapor flux or salt rejection as shown by the solid squares in Figure 3. The water flux was stable and identical to the initial flux, and the salt rejection was always $\sim 100 \%$. The anti-wetting property of the omniphobic membrane is attributable to the reentrant surface structure formed by the clustered SiNPs, which together with the low surface tension due to surface fluorination and PVDF-HFP coating enables a metastable Cassie-Baxter state for the local liquid-membrane-vapor interface. For the feed solution to wick the membrane pores, the system has to undergo a transition from the Cassie-Baxter state, in which vapor/air is entrapped, to the Wenzel state, in which the solid-liquid interface is maximized. With a reentrant structure, such a transition has to overcome a significant energy barrier, rendering the propagation of the liquid-air interface within the membrane pores unfavorable. ${ }^{35}$

Implications. We have demonstrated that our fabricated omniphobic membrane can sustain robust DCMD operation with feed solutions containing surfactants. Such feed solutions readily wet a conventional hydrophobic (e.g., PTFE) microporous membrane, resulting in failure of the membrane to act as a barrier to salt. Although our experiments were conducted in DCMD configuration with an SDS feed solution, similar anti-wetting performance for the omniphobic membrane would be expected for other MD configurations, such as air-gap $\mathrm{MD}$, vacuum $M D$, and sweeping gas $M D$, and with other low surface tension contaminants.

As a low-capital cost membrane-based thermal separation process that can utilize low-grade heat, $\mathrm{MD}$, with conventional hydrophobic but oleophilic membranes, is limited to treat only relatively "clean" water sources with minimal surface active agents. The omniphobic membrane developed in this study, however, may open up vast opportunities for $\mathrm{MD}$ to extend its application for direct desalination of wastewaters with low surface tension contaminants, such as shale gas wastewater and other industrial wastewaters, for beneficial water reuse and resource recovery.

Despite the promising prospect of $\mathrm{MD}$ with an omniphobic membrane, further studies are needed to explore other fabrication techniques and optimize membrane performance. It is also critical to test the omniphobic membrane with a broad spectrum of surface active agents and with feed waters of more complex organic compositions.

\section{ASSOCIATED CONTENT}

\section{S Supporting Information}

Details of the glass fiber membrane modification procedures (including synthesis of the silica nanoparticles) and direct contact membrane distillation experiments. This material is available free of charge via the Internet at http://pubs.acs.org.

\section{AUTHOR INFORMATION}

\section{Corresponding Author}

*E-mail: menachem.elimelech@yale.edu.

\section{Notes}

The authors declare no competing financial interest.

\section{ACKNOWLEDGMENTS}

We acknowledge the support received from the Advanced Research Projects Agency-Energy via Grant DE-AR0000306. We also thank the Pall Corporation for generously providing the PTFE membrane and the Yale Institute for Nanoscience and Quantum Engineering (YINQE) for access to the scanning electron microscopy facility.

\section{REFERENCES}

(1) Lawson, K. W.; Lloyd, D. R. Membrane distillation. J. Membr. Sci. 1997, 1-25.

(2) Souhaimi, M. K.; Matsuura, T. Membrane Distillation; Elsevier: Amsterdam, The Netherlands, 2011.

(3) Alkhudhiri, A.; Darwish, N.; Hilal, N. Membrane distillation: A comprehensive review. Desalination 2012, 287, 2-18.

(4) Alklaibi, A. M.; Lior, N. Membrane-distillation desalination: Status and potential. Desalination 2005, 171, 111-131.

(5) Curcio, E.; Drioli, E. Membrane distillation and related operations-A review. Sep. Purif. Rev. 2005, 34, 35-86.

(6) El-Bourawi, M. S.; Ding, Z.; Ma, R.; Khayet, M. A framework for better understanding membrane distillation separation process. $J$. Membr. Sci. 2006, 285, 4-29.

(7) Xie, M.; Nghiem, L. D.; Price, W. E.; Elimelech, M. A forward osmosis-membrane distillation hybrid process for direct sewer mining: System performance and limitations. Environ. Sci. Technol. 2013, 47, 13486-13493.

(8) Cath, T. Y.; Adams, D.; Childress, A. E. Membrane contactor processes for wastewater reclamation in space: II. Combined direct osmosis, osmotic distillation, and membrane distillation for treatment of metabolic wastewater. J. Membr. Sci. 2005, 111-119.

(9) Lin, S.; Yip, N. Y.; Cath, T. Y.; Osuji, C. O. Hybrid pressure retarded osmosis-membrane distillation system for power generation from low-grade heat: Thermodynamic analysis and energy efficiency. Environ. Sci. Technol. 2014, 48, 5306-5313.

(10) Lin, S.; Yip, N. Y.; Elimelech, M. Direct contact membrane distillation with heat recovery: Thermodynamic insights from module scale modeling. J. Membr. Sci. 2014, 453, 498-515.

(11) Elimelech, M.; Phillip, W. A. The future of seawater desalination: Energy, technology, and the environment. Science 2011, 333, 712-717.

(12) Banat, F.; Jwaied, N. Economic evaluation of desalination by small-scale autonomous solar-powered membrane distillation units. Desalination 2008, 220, 566-573.

(13) Al-Obaidani, S.; Curcio, E.; Macedonio, F.; Drioli, E. Potential of membrane distillation in seawater desalination: thermal efficiency, sensitivity study and cost estimation. J. Membr. Sci. 2008, 85-98.

(14) Kim, Y.-D.; Thu, K.; Ghaffour, N.; Choon Ng, K. Performance investigation of a solar-assisted direct contact membrane distillation system. J. Membr. Sci. 2013, 427, 345-364.

(15) Shaffer, D. L.; Arias Chavez, L. H.; Ben-Sasson, M.; RomeroVargas Castrillón, S.; Yip, N. Y.; Elimelech, M. Desalination and reuse of high-salinity shale gas produced water: Drivers, technologies, and future directions. Environ. Sci. Technol. 2013, 47, 9569-9583.

(16) Khayet, M.; Matsuura, T.; Mengual, J. I.; Qtaishat, M. Design of novel direct contact membrane distillation membranes. Desalination 2006, 192, 105-111.

(17) Franken, A. C. M.; Nolten, J. A. M.; Mulder, M. H. V.; Bargeman, D.; Smolders, C. A. Wetting criteria for the applicability of membrane distillation. J. Membr. Sci. 1987, 33, 315-328.

(18) Song, L.; Li, B.; Sirkar, K. K.; Gilron, J. L. Direct contact membrane distillation-based desalination: Novel membranes, devices, larger-scale studies, and a model. Ind. Eng. Chem. Res. 2007, 46, 23072323.

(19) Kargbo, D. M.; Wilhelm, R. G.; Campbell, D. J. Natural gas plays in the Marcellus Shale: Challenges and potential opportunities. Environ. Sci. Technol. 2010, 44, 5679-5684. 
(20) Vidic, R. D.; Brantley, S. L.; Vandenbossche, J. M.; Yoxtheimer, D.; Abad, J. D. Impact of Shale Gas development on regional water quality. Science 2013, 340, 1235009.

(21) Peng, P.; Fane, A. G.; Li, X. Desalination by membrane distillation adopting a hydrophilic membrane. Desalination 2005, 173, $45-54$.

(22) Razmjou, A.; Arifin, E.; Dong, G.; Mansouri, J.; Chen, V. Superhydrophobic modification of $\mathrm{TiO}_{2}$ nanocomposite PVDF membranes for applications in membrane distillation. J. Membr. Sci. 2012, 415-416, 850-863.

(23) Liu, M.; Wang, S.; Jiang, L. Bioinspired multiscale surfaces with special wettability. MRS Bull. 2013, 38, 375-382.

(24) Wong, T.-S.; Sun, T.; Feng, L.; Aizenberg, J. Interfacial materials with special wettability. MRS Bull. 2013, 38, 366-371.

(25) Sun, T.; Feng, L.; Gao, X.; Jiang, L. Bioinspired surfaces with special wettability. Acc. Chem. Res. 2005, 644-652.

(26) Liu, K.; Tian, Y.; Jiang, L. Bio-inspired superoleophobic and smart materials: Design, fabrication, and application. Prog. Mater. Sci. 2013, 58, 503-564.

(27) Liu, K.; Yao, X.; Jiang, L. Recent developments in bio-inspired special wettability. Chem. Soc. Rev. 2010, 39, 3240-3255.

(28) Zhang, L.; Zhong, Y.; Cha, D.; Wang, P. A self-cleaning underwater superoleophobic mesh for oil-water separation. Sci. Rep. 2013, DOI: $10.1038 /$ srep02326.

(29) Tuteja, A.; Choi, W.; Mabry, J. M.; McKinley, G. H.; Cohen, R. E. Robust omniphobic surfaces. Proc. Natl. Acad. Sci. U.S.A. 2008, 105, 18200-18205.

(30) Sheen, Y.-C.; Huang, Y.-C.; Liao, C.-S.; Chou, H.-Y.; Chang, F.C. New approach to fabricate an extremely super-amphiphobic surface based on fluorinated silica nanoparticles. J. Polym. Sci., Part B: Polym. Phys. 2008, 46, 1984-1990.

(31) Wang, H.; Zhou, H.; Gestos, A.; Fang, J.; Niu, H.; Ding, J.; Lin, T. Robust, electro-conductive, self-healing superamphiphobic fabric prepared by one-step vapour-phase polymerisation of poly $(3,4-$ ethylenedioxythiophene) in the presence of fluorinated decyl polyhedral oligomeric silsesquioxane and fluorinated alkyl silane. Soft Matter 2013, 9, 277-282.

(32) Pan, S.; Kota, A. K.; Mabry, J. M.; Tuteja, A. Superomniphobic surfaces for effective chemical shielding. J. Am. Chem. Soc. 2013, 135, $578-581$.

(33) Tuteja, A.; Choi, W.; McKinley, G. H.; Cohen, R. E.; Rubner, M. F. Design parameters for superhydrophobicity and superoleophobicity. MRS Bull. 2011, 33, 752-758.

(34) Butt, H.-J.; Semprebon, C.; Papadopoulos, P.; Vollmer, D.; Brinkmann, M.; Ciccotti, M. Design principles for superamphiphobic surfaces. Soft Matter 2012, 9, 418-428.

(35) Tuteja, A.; Choi, W.; Ma, M.; Mabry, J. M.; Mazzella, S. A.; Rutledge, G. C.; McKinley, G. H.; Cohen, R. E. Designing superoleophobic surfaces. Science 2007, 318, 1618-1622.

(36) Guo, M.; Ding, B.; Li, X.; Wang, X.; Yu, J. Amphiphobic nanofibrous silica mats with flexible and high-heat-resistant properties. J. Phys. Chem. C 2009, 114, 916-921.

(37) Wong, T. S.; Kang, S. H.; Tang, S.; Smythe, E. J.; Hatton, B. D. Bioinspired self-repairing slippery surfaces with pressure-stable omniphobicity. Nature 2011, 477, 443-447.

(38) Zhou, H.; Wang, H.; Niu, H.; Gestos, A.; Lin, T. Robust, selfhealing superamphiphobic fabrics prepared by two-step coating of fluoro-containing polymer, fluoroalkyl silane, and modified silica nanoparticles. Adv. Funct. Mater. 2013, 23, 1664-1670.

(39) Leng, B.; Shao, Z.; de With, G.; Ming, W. Superoleophobic cotton textiles. Langmuir 2009, 25, 2456-2460.

(40) Stöber, W.; Fink, A.; Bohn, E. Controlled growth of monodisperse silica spheres in the micron size range. J. Colloid Interface Sci. 1968, 26, 62-69. 